PONTIFÍCIA UNIVERSIDADE CATÓLICA do RIO dE JANEIRO

\title{
Fatores que Influenciam o Vínculo de Trabalhadores Voluntários do Colégio CEPRAMOS
}

Aline Moraes Menezes Xavier

Trabalho de Conclusão de Curso

Centro de ciências socials - CCS

DEPARTAMENTO DE ADMINISTRAÇÃO

Graduação em Administração de Empresas 
Aline Moraes Menezes Xavier

Fatores que Influenciam o Vínculo de Trabalhadores Voluntários do Colégio CEPRAMOS

Trabalho de Conclusão de Curso

Trabalho de Conclusão de Curso, apresentado ao programa de graduação em Administração da PUC-Rio como requisito parcial para a obtenção do titulo de graduação em Administração.

Orientador(a): Flávia Cavazzotte

Rio de Janeiro, 04 de junho de 2018. 


\section{Agradecimentos}

Ao meu Deus toda a honra e toda a glória, O louvo pela oportunidade de pertencer ao corpo discente desta faculdade renomada como a PUC-Rio e por estar concluindo este importante ciclo da vida.

Louvo a Deus pelos meus queridos pais, Marcio e Eliane, que com muita dedicação e paciência auxiliaram na minha caminhada, tornando-a mais simples e prazerosa durante estes longos anos de estudo.

Louvo a Deus pelo meu esposo Leandro Xavier por me conceder todo apoio, constante compreensão, participação e intensa intercessão por mim em todas as fases da minha vida acadêmica.

Louvo a Deus pela querida Professora e orientadora Flávia Cavazzotte, que me deu a honra de poder ter acesso ao seu vasto conhecimento e aprender ainda mais com a confecção deste trabalho e por dispor de seu tempo para me auxiliar. 


\section{Resumo}

Menezes Xavier, Aline. Fatores que influenciam o vínculo de trabalhadores voluntários do Colégio CEPRAMOS. Rio de Janeiro, 2018. p.32. Trabalho de Conclusão de Curso - Departamento de Administração. Pontifícia Universidade Católica do Rio de Janeiro.

Este estudo tem por objetivo descrever e analisar os fatores que influenciam os vínculos que se estabelecem entre os trabalhadores voluntários de uma Instituição de Ensino do Terceiro Setor. A pesquisa contou com 12 entrevistados de 41 voluntários totais, distribuídos por diferentes áreas de atuação no Colégio. O método de pesquisa utilizado foi o estudo qualitativo, através de entrevistas com profundidade, com característica exploratória, utilizando-se um roteiro semiestruturado para guiar a entrevista. A análise foi dividida em duas áreas: motivações e integração do indivíduo. Os temas emergentes foram inserção no mercado de trabalho, a visão da organização, a autorrealização e a ambiência; os sentimentos despertados como amor foram determinantes para o processo de vínculos dos voluntários. Quanto à integração do indivíduo, o que a organização agrega a sua vida ou dia a dia, a partir da análise foram levantados os temas de crescimento pessoal e crescimento profissional, fatores importantes para a definição do tipo de vínculo organizacional da Instituição de Ensino. A partir desta análise pode-se concluir que que fatores estão associados ao comprometimento afetivo e à identificação organizacional dos funcionários.

Palavras-chave

Vínculos Organizacionais, Comprometimento Organizacional, Identificação Organizacional, terceiro setor, Voluntariado, Estudo Qualitativo 


\section{Abstract}

Menezes Xavier, Aline. Factors that influence the bonding of voluntary workers of CEPRAMOS College. Rio de Janeiro, 2018. p.32. Trabalho de Conclusão de Curso - Departamento de Administração. Pontifícia Universidade Católica do Rio de Janeiro.

The purpose of this study is to describe and analyze the factors that influence the relationships between volunteer workers in a Third Sector Education Institution. The survey counted on 12 interviewed of 41 total volunteers, distributed by different areas of action in the College. The research method used was the qualitative study, through interviews with depth, with exploratory characteristic, using a semi-structured script to guide the interview. The analysis was divided into two areas: motivation and individual integration. The emerging themes were insertion in the labor market, the organization's vision, self-realization and ambience; the feelings awakened as love were decisive for the bonding process of the volunteers. Regarding the integration of the individual, what the organization adds to his life or day to day, from the analysis were raised the themes of personal growth and professional growth, important factors for the definition of the type of organizational bonding of the Teaching Institution. From this analysis it can be concluded that the factors are associated with affective commitment and the organizational identification of employees.

\section{Key-words}

Organizational Bondings, Organizational Commitment, Organizational Identification, Third Sector, Volunteering, Qualitative Study 


\section{Sumário}

1 Introdução

2 Revisão de literatura 3

2.1. Trabalho Voluntário 3

2.1.1. Trabalho voluntário: definições 3

2.1.2. As motivações para o Voluntariado 4

2.2. Conceitos que Discutem Vínculos com as Empresas 6

2.2.1. Comprometimento 6

2.2.2. Identificação Organizacional 9

2.2.3. Diferenças entre Identificação Organizacional e Comprometimento11

3 Metodologia 13

3.1. Descrição da Empresa 13

3.2. Coleta de Dados 14

$\begin{array}{ll}\text { 3.3. Perfil dos Entrevistados } & 15\end{array}$

4 Análise dos Resultados 16

4.1. Motivações para o Trabalho Voluntário 16

4.1.1. Motivos de pertencer a organização 16

4.1.2. Sentimentos sobre a Organização 19

4.1.3. Visão do funcionário sobre a Instituição 20

4.2. Integração do Indivíduo à Organização 22

$\begin{array}{ll}5 \text { Conclusão } & 24\end{array}$

$\begin{array}{ll}6 \text { Referências Bibliográficas } & 26\end{array}$ 


\section{Lista de Quadros}

Quadro 1 Roteiro da Entrevista ......................................................... 14

Quadro 2 Perfil dos Entrevistados ........................................................... 15

Quadro 3 Conceitos Emergentes e Categorias Preliminares .......................... 17

Quadro 4 Sentimentos ..................................................................... 19

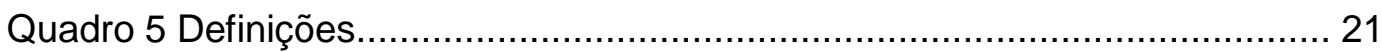

Quadro 6 Conceitos Emergentes e Categorias Preliminares - Integração do Indivíduo................................................................................................. 22

\section{Lista de Gráficos}

Gráfico 1 Sentimentos ........................................................................ 20

Gráfico 2 Definições ....................................................................... 21 


\section{Introdução}

De acordo com a pesquisa feita pelo IBGE (2016), cerca de 6,5 milhões de pessoas fazem trabalho voluntário no Brasil, o que representa $3,9 \%$ da população de mais de 14 anos, sendo 91,5\% em Organizações Não Governamentais ou empresas, o restante, individualmente. Ao falarmos dos ambientes de realização do voluntariado, a pesquisa realizada mostra que $81,5 \%$ do total eram em congregações religiosas, condomínios, sindicatos, partidos, escolas, hospitais ou asilos.

Esta monografia aborda o tema de Identificação Organizacional e Comprometimento em uma organização de cunho social, tendo como objeto de estudo o Centro Educacional do Primeiro Amor Obras Sociais - CEPRAMOS, uma empresa do setor educacional com colaboradores com contratos de trabalho voluntário.

Dentro da área de Comportamento Organizacional há dois conceitos que retratam o vínculo de um funcionário em uma empresa, um deles é o Comprometimento Organizacional e o outro é a Identificação Organizacional. O comprometimento organizacional é o desejo e a vontade de um funcionário de contribuir para o sucesso de uma organização (Sani,2013). Meyer e Allen (1997) acreditam que dependendo dos motivos que fazem os colaboradores se comprometerem com a organização em que estão inseridos, existem três tipos diferentes de comprometimento organizacional, o Comprometimento Afetivo, o Comprometimento Normativo e o Comprometimento Instrumental. De acordo com Fernandes, Marques e Carrieri (2009) devido à identificação organizacional, o funcionário consegue se conectar e se ver como parte da empresa, causando o anseio de pertencimento a esta e, já que a identificação pode influenciar o comportamento do indivíduo e as atitudes tomadas na empresa (Riketta, 2005), é um ponto que deve ser levantado e questionado de sua influência na organização.

Apesar de um indivíduo estabelecer vínculos com a empresa, isso não traz garantias de que os objetivos sejam alcançados sem barreiras, mas o compromete com o desempenho e com os resultados adquiridos, já que ele se sente efetivamente identificado, pertencente e participante da organização; sendo assim, os vínculos são capazes de influenciar o funcionamento das empresas. Deste modo, avaliar o processo de vinculação é um tema de grande relevância para se caracterizar e compreender a dinâmica das relações nas organizações. 
O presente estudo tem o objetivo de descrever e analisar os fatores que influenciam os vínculos que se estabelecem entre os trabalhadores voluntários de uma Instituição de Ensino do Terceiro Setor com a Instituição de Ensino CEPRAMOS. O trabalho analisa os motivos pelos quais eles continuam participando voluntariamente desta organização. Para determinar esses fatores, foram realizadas entrevistas com profundidade, uma abordagem qualitativa exploratória, analisando os voluntários com suas motivações, sentimentos e visão sobre a organização, buscando assim fatores que influenciam no vínculo organizacional.

A relevância do estudo apresentado é para gestores de ONG's, organizações e projetos sociais que atuem com colaboradores por meio de voluntariado, ou parte deles, e possam ter uma base de estudo para atentar aos aspectos que motivam seus funcionários a se vincularem a organização, já que a Identificação Organizacional e Comprometimento Organizacional em empresas do terceiro setor, não possuem estudos encontrados, e, por fim, para todos os estudiosos que possuem interesse na área em questão. 


\section{Revisão de literatura}

Para a realização do presente estudo, neste capítulo serão abordados os aspectos teóricos para darem o alicerce necessário para a sustentação da análise a ser realizada sobre os fatores de motivação do vínculo dos voluntários do Colégio CEPRAMOS.

\subsection{Trabalho Voluntário}

De acordo com o Centro de Voluntariado de São Paulo (CVSP, 2001), o início da história de trabalhos voluntários no Brasil foi na fundação da Santa Casa da Misericórdia em 1543, com foco no âmbito de assistência social, a partir da necessidade de cuidados com a população mais desprovida, surgimento de doenças e epidemias por todo o território, sendo estas mais desastrosas nas áreas de maior carência; e com foco da religião, já que inicialmente o trabalho era realizado, em sua maioria, por mulheres com vínculos à Igreja Católica. $O$ voluntariado, a partir deste marco, foi expandido com base nos preceitos religiosos, sendo, até os dias de hoje, presentes nas motivações e objetivos de muitas instituições que atuam nesse papel.

Nos anos 80, foram criadas as Organizações Não-Governamentais (ONG's), instituições privadas que não possuem fins lucrativos, são grandes exemplo de voluntariado, onde todos os recursos arrecadados são voltados diretamente para as atividades e objetivos da organização. Com essa criação foi mais disseminado o trabalho voluntário, dando abertura para a diversificação de áreas de atuação (Lima e Bareli, 2010).

De acordo com Lima e Bareli (2010) o trabalho voluntário nos anos 90 ganhou incentivos com as medidas governamentais, sendo a criação da Lei do Trabalho Voluntário em 1998 e iniciativas privadas. Por fim, nos anos 2000 até o presente momento muitas ONG's foram estabelecidas e o aumento de trabalhos voluntários informais, como por exemplo as Ações Sociais, que são voltadas para atenção em diversas áreas, como a Medicina, Direito, Odontologia, Contabilidade, etc. a auxiliar a população mais desprovida.

\subsubsection{Trabalho voluntário: definições}

Ao conceituarmos o trabalho voluntário, deparamos com duas vertentes de definições mais abrangidas pelos estudos sobre o assunto, onde as atitudes são voltadas para comunidades e pessoas com necessidades maiores do que 
aquele quem presta o serviço, ou, doar o seu tempo para atividades que não possuem remuneração financeira (Lima e Bareli, 2010). Existe o trabalho voluntário formal, o qual é prestado por organizações ou em conjunto com estas, e o trabalho voluntário informal, onde, é a ajuda a vizinhos, familiares e amigos (Lima e Bareli, 2010). Skin e Kleiner (2003) define o trabalho voluntário como pessoas que dedicam seu tempo e serviço a uma organização, sem receber uma compensação financeira, tendo como consequência benefício próprio ou do próximo; não considerando o trabalho voluntário informal.

O trabalho voluntário segundo a definição da Organização das Nações Unidas - ONU (art. $.2^{\circ} .^{\circ}$ da Lei n. 71/98, de 3 de novembro), é um conjunto de ações de interesse comunitário e social, concretizadas de maneira desinteressada por pessoas, no âmbito de projetos, programas e outras maneiras de intervenção ao serviço dos indivíduos, das famílias e da comunidade, desenvolvidos sem fins lucrativos por entidades públicas ou privadas. Em 2001, com intuito de estimular a prática de voluntariado, a ONU declarou este ano como o Ano Internacional do Voluntariado (Souza e Lautert, 2007).

O trabalho voluntário no Brasil é regido pelo art. 1ํ da Lei № 9.608, criada em 1998, define o voluntariado como atividade não remunerada, prestada por pessoa física a entidade pública de qualquer natureza, ou a instituição privada de fins não lucrativos, que tenha objetivos cívicos, culturais, educacionais, científicos, recreativos ou de assistência social, inclusive mutualidade (Constituição Brasileira, 1988).

\subsubsection{As motivações para o Voluntariado}

De acordo com Lathan e Pinder (2005), a motivação para as tarefas é um conjunto de forças que fazem com que o indivíduo comece um comportamento relacionado com o trabalho e determine o seu método, direção, magnitude e permanência.

Ferreira, Proença e Proença (2008) proferem que ao analisar a ampla literatura existente que discursa sobre comportamento de profissionais nas empresas, não é possível atrelar as mesmas características àqueles que trabalham como voluntários, devido a diferenças substantivas entre os dois tipos de trabalho. De acordo com Cnaan e Cascio (1998), as divergências pairam sobre a motivação, remuneração financeira, ao tempo dedicado e disponível para a realização do trabalho, os voluntários estarem em mais do que uma 
organização e a captação dos voluntários possui caráter informal; os preceitos e valores das organizações nem sempre são acolhidas no voluntariado e a falta de avaliação das ações do voluntário, para não haver questionamentos sobre níveis de entrega de resultados do indivíduo.

Bussell e Forbes (2002) mencionam que o sucesso em recrutar e reter os voluntários na organização se dá a partir do entendimento das motivações dos voluntários, e muitos estudos foram realizados para entenderem porque os indivíduos se voluntariam e quais os benefícios estes recebem com o voluntariado. Indivíduos diferentes podem estar envolvidos nas mesmas atividades, mas terem objetivos diferentes.

É de fato evidência que o altruísmo seja uma das motivações nas atividades voluntárias. Na pesquisa realizada por Nichols e King (1998) foi definido que uma das motivações era o desejo de ajudar as pessoas, o apoio aos outros é um fator importante para aqueles que praticam ao voluntariado; mas Cnaan e Goldberg-Glendem (1991), afirmam que não é apenas o fator altruístico, mas também o egoísmo, já que exercem a função de voluntariado para satisfazer importantes objetivos sociais e psicológicos, como por exemplo, de acordo com Bussell e Fobes (2002), uma das motivações é tentar suprir algum serviço que está em carência ou precário para a família, ou seja, o voluntário entra na organização com a pretensão de beneficiar um membro familiar.

Okun e Eisenberg (1992) acreditam que algumas das motivações do voluntariado são: a necessidade de se sentir útil e produtivo, principalmente para os de maior idade; o pertencimento à organização; a necessidade de afiliação; o ganho de prestígio ou autoestima; ou, uma maneira de fazer amigos.

A melhoria do capital humano parece ser um importante motivador para o voluntariado. Rifkin (1999) ressalta que o voluntariado fornece emprego aos desempregados, podendo ajudar o voluntário a desenvolver habilidades que possam ser úteis na carreira futura ou ajudar a obter um emprego, de forma que possa ganhar confiança e se preparar para o mercado de trabalho, ganhando habilidades importantes para a sua atuação no mercado.

De acordo com Snyder e Debono (1999), a principal motivação está atrelada aos valores, denominando como "função expressiva de valor". O voluntariado permite que o indivíduo aja de maneira em que seus valores subjacentes, seu verdadeiro "eu" e a expressão de suas crenças para passá-las para os outros, como por exemplo, o envolvimento religioso e as crenças 
religiosas, as quais mostraram-se associadas a uma maior probabilidade de voluntariado.

O estudo feito por Ferreira, Proença e F. Proença (2008) conclui que dentro de vários autores, aqui citados, as motivações em destaque são: 0 altruísmo - o querer ajudar ao próximo, fazer algo que vale a pena e ser solidário; o sentimento de pertencimento - fazer o contato social, ser bem aceito em comunidade, ter contato com pessoas de mesmos interesses; ego e reconhecimento social - contatos institucionais, sentimentos de autoestima, satisfação, interesse nas atividades da organização; e por fim, aprendizagem e desenvolvimento - experiências, enriquecimento pessoal, escada para um emprego futuro.

\subsection{Conceitos que Discutem Vínculos com as Empresas}

Os vínculos fazem parte de toda maneira de relacionamento humano. Bion (1970 apud Romero e Garcia, 2011) assegura que o vínculo pode ser apresentado como uma experiência emocional em que dois indivíduos estão conexos entre si, ponderando que existem emoções fundamentais que inevitavelmente se encontram presentes em toda relação vincular.

Chanlat (1996) acreditava que a pessoa vê seu anseio e sua existência sendo reconhecidos pelas relações que mantém um com o outro, na identificação mútua. Zimermann (1997 apud Romero e Garcia, 2011) afirmam que é na relação com o semelhante que o indivíduo se constitui, se reconhece, satisfaz ou não os seus desejos. Conforme a empresa é composta por indivíduos, torna-se essencial ao seu funcionamento a interação afetiva entre seus funcionários.

\subsubsection{Comprometimento}

O comprometimento organizacional não possui um conceito unitário, já que existem diferentes tipos de compromisso com a organização (Lau, 2011). Para Sani (2013) o comprometimento organizacional refere-se ao desejo e a vontade de um funcionário de contribuir para o sucesso de uma organização. Rego (2002) afirma que o comprometimento organizacional pode ser entendido como ligações psicológicas que são forjadas entre os indivíduos e a organização. A crença subjacente é que o compromisso dos indivíduos induz efeitos positivos sobre a eficácia das organizações onde trabalham, sendo até mesmo capazes 
de suportar condições de trabalho altamente exigentes. Salles e Balassiano (2012) afirmam que este fato tem sua origem nos laços emocionais do indivíduo com a organização, representados por lealdade, apego e confiança.

Ellenbecker e Cushman (2012) definiram o compromisso organizacional como as várias razões que direcionam a associação de um funcionário a uma organização. Dentre estas razões incluíam-se o apego, vínculo emocional e obrigação. Dependendo das razões pelas quais os funcionários se comprometem com suas organizações, três tipos diferentes de compromisso organizacional existem, de acordo com o modelo tridimensional de Meyer e Allen produzido em 1997, o Comprometimento Afetivo, Instrumental e Normativo. Anthony e Berete (2016) afirmam que o comprometimento afetivo, o qual ocorre quando os funcionários continuam na organização, deve-se a sua satisfação e pelo sentimento de pertencimento à organização. Balassiano e Salles (2012 apud Anthony e Berete, 2016) afirmam que o comprometimento instrumental ocorre quando os funcionários permanecem na organização por causa do reconhecimento dos custos associados à saída da organização. E, por fim, o compromisso normativo ocorre quando os funcionários se comprometem por causa de uma obrigação moral de permanecer na organização e os funcionários sentem que devem permanecer na organização. Estes diferentes tipos de compromisso são feitos para serem diversamente afetados por vários fatores.

De acordo com Allen e Meyer at. all (1996 apud Balassiano e Salles, 2012) aqueles empregados com comprometimento afetivo são menos propensos a abdicar do emprego e apresentar menor absentismo, quando contrastado, por exemplo, com aqueles com compromisso de continuidade. Além disso, o comprometimento afetivo está mais relacionado ao maior desempenho. Em outras palavras, há evidências de que o desejo de indivíduos para contribuir com os objetivos organizacionais é influenciada pela natureza dos laços psicológicos que os ligam à organização. Rego (2002) declara que existe mais probabilidade que indivíduos sejam mais propensos a grandes esforços para ter um bom desempenho quando sentem a necessidade de permanecer na organização, do que quando se sentem obrigados a permanecerem lá. O comprometimento afetivo mostra que o indivíduo possui menores finalidades de deixar a organização, desprezíveis índices de faltas de trabalho, maior atitude de exercer os deveres e diretos; e desempenho nos afazeres com maior grau de sucesso.

Ao falar do comprometimento afetivo, Meyer e Allen (1996 apud Hall et all, 1997), acreditam que as etapas em que os objetivos da empresa e do indivíduo se tornam um, ou seja, se integram; sendo assim, esse modelo de 
comprometimento seria acometido por experiências prévias, principalmente aquelas que satisfazem necessidades psicológicas, induzindo o conforto na organização e a competência em seus afazeres.

Simon e Coltre (2012) afirmam que existem indicadores do comprometimento afetivo, dentre estes estão: a felicidade do indivíduo em dedicar o resto de sua carreira na organização, a percepção dos problemas organizacionais como se fossem dele, o forte senso de integração com a organização, o seu vínculo emocional com a organização e o imenso significado pessoal que a organização proporciona ao indivíduo. Ao medir estes indicadores, pode-se concluir o grau de comprometimento afetivo do indivíduo com a organização em que está inserido.

Orife, Slack e Anderson (2012) afirmam que o compromisso normativo se baseia em deveres e valores, e no grau em que um funcionário fica em uma organização por um sentimento de obrigação, pois este vem de um senso de dever moral e do sistema de valores de um indivíduo. Pode ser um resultado de compromisso afetivo, ou um resultado de socialização no local de trabalho e compromisso com colegas de trabalho. O comprometimento normativo é maior em organizações que valorizam a lealdade e comunicam sistematicamente o fato aos funcionários com recompensas, incentivos e outras estratégia. Altos níveis de satisfação no trabalho, por sua vez, reduzem a rotatividade de funcionários e aumentam a capacidade da organização de recrutar e reter talentos.

Kaur e Sandhur (2010) afirma que o compromisso normativo se desenvolve em resposta a várias experiências de pré-entrada, e como resultado de experiências de socialização que enfatizam a adequação de permanecer fiel ao empregador.

Simon e Coltre (2012) afirmam que os indicadores de comprometimento normativo são: a obrigação do indivíduo em permanecer na organização, o fato de não achar certo, mesmo sendo vantajoso para ele; deixar a organização no presente momento, o sentimento de culpa caso deixasse a organização agora; a lealdade do indivíduo perante a ela, a obrigação moral do indivíduo com as pessoas do seu trabalho e o sentimento de dever para com a organização. Ao medir estes indicadores, pode-se concluir o grau de comprometimento normativo do indivíduo com a organização em que está inserido.

Orife, Slack e Anderson (2012) acreditam que quando o compromisso de continuidade não é completamente impulsionado pelo comprometimento afetivo, geralmente se resume aos custos que um funcionário associa a deixar a organização. O comprometimento de continuidade também é impulsionado em 
grande parte pela cultura organizacional e, quando um funcionário acha que uma organização é positiva e de apoio, ele terá um maior grau de comprometimento contínuo. Fatores organizacionais importantes, como fidelidade dos funcionários e retenção de funcionários, são componentes do compromisso instrumental.

Kaur e Sandhu (2010) acreditam que o comprometimento instrumental, presumivelmente, se desenvolve quando os funcionários reconhecem que eles acumularam investimentos ou apostas secundárias que seriam perdidas se eles deixassem a organização ou como eles reconhecem que a disponibilidade de alternativas, comparáveis a esta em que estão inseridos, são limitadas.

Fedvyczyk e Souza (2013) define a dimensão instrumental como no momento em que os indivíduos exercem suas atividades mais por necessidade e carência de opções imediatas de ocupação do que porque almejam e estão preparados a se doar em favor do crescimento da organização; compreendendose assim que o indivíduo enxerga a organização como uma fonte de renda, onde possui uma troca entre o empregado que entra com o esforço de trabalho e a organização que adentra com a gratificação financeira.

\subsubsection{Identificação Organizacional}

A identificação organizacional é definida por Dutton, Dukerich e Harquail (1994 apud Beyda e Macedo Soares, 2010) como o nível em que o indivíduo possui em sua autoconcepção atributos da organização em que atua. Os autores Tajfel e Turner em 1979 foram os que trouxeram a discussão da identificação organizacional com a Teoria da Identidade Social, que é definida como a formação de autoimagem de um indivíduo por uma identidade pessoal que conglomera atributos próprios, sejam estes os interesses e capacidades, e por uma identidade social desenvolvida a partir de seus grupos de pertencimento (Mendes, 2014)

Woksness (2014) afirma que os fundamentos da identificação organizacional se baseiam em uma noção de que os membros compartilham um senso de semelhança com cada um em termos de interesses e objetivos. Além disso, o componente de solidariedade ressalta a importância para o senso de pertencimento dos membros com a organização. O pertencimento a equipes de trabalho é considerado por Bergami e Bagozzi (2000 apud Mendes, 2014) uma das primordiais vinculações que um indivíduo pode ter, possivelmente uma das mais relevantes do que quaisquer afiliações a outros grupos sociais, sejam estes o sexo, a idade ou a etnia. 
Fernandes (2009 apud Santos, Vieira e Garcia, 2013), a definição de identificação organizacional agrupa os valores e crenças entendidas pelos indivíduos como aquelas que em sua concepção são páreas com os da organização que está inserido, inclui o senso de pertencimento entre estes e a organização, quando suas crenças sobre a empresa viram referências para o seu autoconceito. Hogg e Terry (2000 apud Santos, Vieira e Garcia, 2013), esse processo de se autodenominar parte do grupo de certa organização pode modificar-se em fonte de autoridade, garantia e satisfação, tendo resultado direto na autoestima do indivíduo. Isso não é decorrente apenas por conta da envoltura afetiva dos indivíduos com a organização, mas também pelo prestígio aos que estão afastados, e que a conceituam como um local com bons atributos, atraindo para esta o desejo de pertencimento.

Pratt (1998) considera que o processo para identificação organizacional está ligado a três aspectos de forma profunda, são estes: a segurança psicológica é a parte do processo que funciona de forma que os indivíduos utilizam um mecanismo de reprodução para resolver a falta de consistência em áreas emocionais; o processo de afiliação é a área que a pessoa tem a necessidade de se sentir parte de um grupo, de pertencer a este como forma de escapar da solidão e não ser isolado socialmente; o processo de autovalorização onde o indivíduo procura reproduzir as atitudes e comportamentos de quem, em sua visão, é uma pessoa importante para seu crescimento pessoal, com finalidade de ter uma construção de uma auto avaliação com resultados positivos; o processo final é chamado de significado, este processo faz com que o indivíduo procure alusões de valores para agrupar a si mesmo, alterando o seu comportamento, de maneira a conceder um desígnio à sua existência, ou seja, um indivíduo que se identifica com a organização, ele não necessariamente precisa atribuir esforços com os objetivos da equipe e da organização, mas sim sentir-se parte do grupo de forma cognitiva e emocional.

A identidade dos indivíduos é uma sinopse de variadas identificações, que vão acontecendo em cargo do atrelamento a distantes grupos sociais, por exemplo, a família, a escola, o trabalho e outras organizações. As probabilidades de identificação são infinitas e não há nenhuma forma de impedir que aconteça (Placer, 1998 apud Davel e Machado, 2010). Dukerich et al. (1998 apud Machado, 2005), a identificação organizacional aparece em coeficientes díspares de intensidade, onde são classificados como forma positiva e negativa, sendo as intensidades quanto mais fortes, mais fundamental será para a definição da identidade organizacional. 
Woksness (2014) remete a identidade organizacional os termos ingroup e outgroup, os quais se referem a como as pessoas classificam a participação no grupo em termos de pertencimento ao grupo. Uma explicação aproximada seria os designados ingroup "nós" e o grupo externo "eles", ou seja, outgroups constituem aqueles que diferem significativamente de nós mesmos e o grupo interno é formado pelos que pertencem.

De acordo com Wokness (2014) a identificação do grupo pode ser alcançada quando um indivíduo cognitivamente vê seu destino como entrelaçado com o do grupo. Entretanto, existe uma discordância quanto ao componente comportamental e afetivo de identificação (Ashford \& Mael, 1989). De acordo com Woksness (2014) Ashforth e Mael viam ambos os componentes como antecedentes potenciais e consequências da percepção cognitiva da participação no grupo, ou, em outras palavras, como precursor e resultado do processo de identificação. Isso, de acordo com os autores, distinguir comportamento e afeto do de identificação, já Tajfel (1982) entretanto, destacou o componente avaliativo e afetivo como componentes necessários na identificação.

No estudo realizado por Woksness (2014), foi levantada a questão de quem nós somos no quesito organização, Machado (2005) responde a partir da citação de Ruano-Borbalan (1998) que é a partir da identidade que existe a identificação, a identidade não pode existir sem a identificação, pois estão relacionadas, ou seja, ela se arquiteta em afinidade com o próximo e com a empresa, sendo assim, o indivíduo está identificado ou não identificado com a organização.

\subsubsection{Diferenças entre Identificação Organizacional e Comprometimento}

Apesar dos desenvolvimentos teóricos e empíricos, permanece uma frequente confusão entre identificação e comprometimento (Riketta, 2005; Van Dick, 2004). Os teóricos da identificação sugeriram que essa confusão decorre, em parte, de conceitos formulados no passado, utilizados até o presente momento sobre o comprometimento organizacional, pois tem sido contextualizado e operacionalizado de forma muito semelhante à identificação (Cardoso, De Castro e Gomes, 2018).

A distinção das duas definições é complexa, pois ambas podem ser consideradas como ligações psicológicas que conectam o indivíduo à empresa 
(Van Knippenberg \& Sleebos, 2006). Van Dick, Becker e Meyer (2006) afirmam que a Identificação e o Comprometimento são de fato conceitos distinguíveis e suas associações com intenções de mudança variam entre as hierarquias organizacionais, estes autores mostram a posição de Herrbach que distingue os conceitos apresentando a relação entre comprometimento organizacional e identificação (inibição comportamental e traços de ativação; estados afetivos positivos e negativos). A identificação organizacional está positivamente relacionada ao afeto negativo quando se controla os traços afetivos e o comprometimento, mas a correlação positiva significativa entre a identificação e o afeto positivo, não permanece mais quando se controla o comprometimento efetivo. Uma implicação teórica interessante desse achado, como sugerido pelo autor, é um possível efeito mediador da identificação pelo comprometimento afetivo em relação à ativação positiva (Van Dick, Becker e Meyer, 2006).

Van Dick, Becker e Meyer (2006) têm um conceito bem interativo entre identificação e comprometimento, eles começam por distinguir estes, de forma que o compromisso é uma força que liga um indivíduo a algum alvo e a um curso de ação de relevância para o alcance deste; já a identificação é a auto definição de um funcionário em termos de sua filiação a um grupo, então, estes autores baseiam-se na identificação de estruturas situadas e profundas e sugerem que a identidade situada está intimamente associada a comportamentos externamente regulados e não discricionários e essa relação é mediada por compromissos baseados em troca (obrigação endividada e compromisso de continuidade). Por outro lado, sugere-se que a identificação em estrutura profunda esteja mais relacionada a comportamentos discricionários autonomamente regulados.

Edwards (2005) explica que em díspares inquéritos as mesmas palavras têm sido utilizadas para descrever ambos os conceitos, como elo, sentimento de pertencimento, afeição, coerência de valores e objetivos, fidelidade, etc. As similaridades ficam em parte a dever-se ao fato de ambos os conceitos apresentarem traços psicológicos semelhantes, existindo conceitos de comprometimento organizacional que agregam a própria identificação. Pode-se dizer que tem sentido distinguir comprometimento e identificação dizendo que o comprometimento abrange identificação (Cardoso, De Castro e Gomes, 2018).

A partir das teorias apresentadas, o objetivo deste trabalho é o estudo sobre vínculos de funcionários voluntários com uma organização do terceiro setor. 


\section{Metodologia}

O estudo se baseia em dados levantados para descrever e analisar os fatores que influenciam os vínculos que se estabelecem entre os trabalhadores voluntários de uma Instituição de Ensino do Terceiro Setor, o Centro Educacional do Primeiro Amor Obras Sociais - CEPRAMOS. Para entendermos o procedimento utilizado para o estudo, serão demonstrados: a Descrição da Empresa, a Coleta de Dados e o Perfil dos participantes da pesquisa. A análise do conteúdo será realizada através das falas dos participantes das entrevistas, identificando temas, conceitos emergentes e categorias preliminares.

\subsection{Descrição da Empresa}

O Centro Educacional do Primeiro Amor Obras Sociais - CEPRAMOS é uma Instituição de Ensino localizada no bairro Vila Valqueire, voltada para alunos de Educação Infantil (Maternal Baby ao Pré II) e Ensino Fundamental I ( $1^{\circ}$ ao $5^{\underline{a}}$ ano), contemplando horários normais e integrais.

A Instituição foi fundada em 1994 pelo General do Exército e Pastor Jesaias dos Anjos, com a intenção em trazer para as crianças a educação moral e cívica que o mesmo recebeu mais jovem, mas também, propagar sua crença (Cristão Protestante) a todos. A Instituição era localizada inicialmente em uma garagem, a qual pertencia a um membro da lgreja em que congregava. A partir daí, em poucos anos migraram para uma casa, no mesmo bairro atual, até que há 10 anos atrás compraram o prédio de três andares, com a ajuda da Igreja Congregacional do Primeiro Amor, o qual utilizam até o momento. A Instituição cresceu e de três alunos iniciais, atualmente são 100 alunos matriculados, sendo $60 \%$ da Educação Infantil.

Sua proposta educacional é de semear em diversas gerações de estudantes, valores fundamentais para uma boa formação humana. Seus valores são baseados em: comprometimento com a qualidade de ensino, disciplina acadêmica, qualidade de vida e autoestima. O modelo de ensino é o Tradicional com o Construtivista, o qual trás para a Educação Infantil, principalmente, a vivência e experiência do lúdico e da realidade e para o Fundamental o método mais Tradicional de Ensino.

Os cargos de professores, auxiliares, direção, coordenação e secretaria são todos com trabalho voluntário, onde não existe vínculo empregatício. Os 
voluntários recebem apenas uma ajuda de custo mensal com direito a passagem. Atualmente são 41 voluntários distribuídos em todas as áreas do Colégio CEPRAMOS, sendo cada voluntário crucial para o funcionamento da Instituição, já que cada papel exercido tem influência no desenvolvimento da escola.

\subsection{Coleta de Dados}

Para a realização deste estudo, o método utilizado para a coleta dos dados necessários foi a pesquisa qualitativa, com entrevistas em profundidade através de um roteiro estruturado para auxiliar no levantamento dos dados, respondido voluntariamente por cada colaborador.

\begin{tabular}{|c|c|}
\hline \multicolumn{2}{|r|}{ Roteiro da Entrevista } \\
\hline 1 & Nome \\
\hline 2 & Idade \\
\hline 3 & Quanto tempo exerce a profissão? \\
\hline 4 & Quanto tempo exerce a profissão na Instituição? \\
\hline 5 & Disciplina que ministra? \\
\hline 6 & Qual ano escolar ministra as aulas? \\
\hline 7 & Como conheceu a escola? \\
\hline 8 & $\begin{array}{l}\text { O que motivou a entrar na instituição? Você poderia estar fazendo várias } \\
\text { coisas, mas porque você está aqui? }\end{array}$ \\
\hline 9 & O que agrega em sua vida estar nesta escola? \\
\hline 10 & $\begin{array}{l}\text { Se você pudesse descrever um sentimento sobre trabalhar aqui, qual } \\
\text { seria? }\end{array}$ \\
\hline 11 & Se você fosse descrever a Instituição com três palavras, quais seriam? \\
\hline 12 & O que mudaria, se pudesse? \\
\hline
\end{tabular}

\section{Quadro 1 Roteiro da Entrevista}

Como o entrevistador faz parte do corpo de voluntários, as entrevistas foram iniciadas explicando a confidencialidade do conteúdo da conversa e o motivo da realização da Pesquisa, a qual, deixando explícito que é para o Trabalho de Conclusão de Curso sobre o Centro Educacional do Primeiro Amor Obras Sociais. A partir do roteiro apresentado no Quadro 1, foram realizadas 12 (doze) entrevistas, entre estas, as perguntas do roteiro foram reformuladas de 
acordo com a necessidade de polir as respostas, para que pudesse ser extraído a maior veracidade nas falas e para ser encontrado pontos de discordância no discurso apresentado, para ser evitado, o máximo possível, as respostas serem falsas, causando influência negativa na análise do estudo.

As entrevistas foram realizadas em salas da Instituição, somente com o participante, para dar mais liberdade e espaço para os voluntários. Estas duraram em média de 8 a 10 minutos. Dentre as 12 entrevistas realizadas, foi excluída uma entrevista devido a interferências de outros voluntários durante a entrevista, que impediu sua conclusão.

\subsection{Perfil dos Entrevistados}

Os entrevistados possuem perfis bem diferenciados, idades que variam de 19 a 60 anos, tempo de profissão de 3 meses a 30 anos e tempo de trabalho na Instituição que variam de 3 meses a 24 anos. Como o corpo de voluntários é $99 \%$ composto por mulheres, as entrevistadas foram respondidas totalmente pelo sexo feminino. Na tabela 1 podemos visualizar o panorama geral do perfil dos entrevistados, contendo seu nome, idade, cargo na Instituição, tempo de profissão e tempo na Instituição.

\begin{tabular}{|c|c|c|c|c|}
\hline Nome & Idade & $\begin{array}{c}\text { Cargo na } \\
\text { Instituição }\end{array}$ & $\begin{array}{c}\text { Tempo de } \\
\text { Profissão }\end{array}$ & $\begin{array}{c}\text { Tempo na } \\
\text { Instituição }\end{array}$ \\
\hline Entrevistada 1 & 49 anos & Auxiliar & 1 ano & 1 ano \\
\hline Entrevistada 2 & 27 anos & Professora & 7 anos & 4 meses \\
\hline Entrevistada 3 & 43 anos & Auxiliar & 2 anos & 2 anos \\
\hline Entrevistada 4 & 31 anos & Auxiliar & 2 anos & 4 meses \\
\hline Entrevistada 5 & 37 anos & Auxiliar & 8 meses & 8 meses \\
\hline Entrevistada 6 & 58 anos & Diretora & 41 anos & 24 anos \\
\hline Entrevistada 7 & 38 anos & Professora & 8 anos & 8 anos \\
\hline Entrevistada 8 & 57 anos & Professora & 9 anos & 1 ano \\
\hline Entrevistada 9 & 47 anos & Professora & 3 anos & 5 meses \\
\hline Entrevistada 10 & 26 anos & Professora & 5 anos & 2 anos \\
\hline Entrevistada 11 & 19 anos & Auxiliar & 1 ano & 1 ano \\
\hline
\end{tabular}

Quadro 2 Perfil dos Entrevistados 


\section{Análise dos Resultados}

As entrevistas realizadas foram analisadas, sendo apresentados aqui os resultados em torno de dois temas: 1) Motivações para o Trabalho Voluntário e 2) Integração do Indivíduo à Organização, estas etapas foram organizadas a partir de conceitos emergentes e categorias preliminares observadas nos relatos dos entrevistados.

\subsection{Motivações para o Trabalho Voluntário}

Esta seção está dividida em três aspectos importantes para a explicação do vínculo organizacional: 1) os motivos de pertencer a organização, 2) os sentimentos gerados pelo pertencimento da organização e 3) a visão do funcionário sobre a Instituição.

\subsubsection{Motivos de pertencer a organização}

No levantamento dos dados, foram definidos quatro conceitos emergentes para a explicação das motivações dos voluntários para estarem na Instituição, os quais são: Inserção no Mercado de Trabalho, Visão da Organização, Autoconceito e a Ambiência.

\begin{tabular}{|c|c|c|}
\hline $\begin{array}{l}\text { Conceito } \\
\text { Emergente }\end{array}$ & $\begin{array}{l}\text { Categoria } \\
\text { Preliminar }\end{array}$ & Trecho da Entrevista \\
\hline \multirow[b]{2}{*}{$\begin{array}{l}\text { Inserção no } \\
\text { Mercado de } \\
\text { Trabalho }\end{array}$} & Desemprego & $\begin{array}{l}\text { "Na realidade quando conversei com a tia Daniele, estava } \\
\text { desempregada e todo mundo sabe da crise em que estamos } \\
\text { vivendo hoje, então quando vi a oportunidade de trabalhar aqui, } \\
\text { resolvi aceitar" (Entrevistada 8) }\end{array}$ \\
\hline & $\begin{array}{l}\text { Experiência } \\
\text { Profissional }\end{array}$ & $\begin{array}{l}\text { "Abracei essa oportunidade como um aprendizado, já que foi } \\
\text { uma escola que me concedeu uma oportunidade de aprender. } \\
\text { Pois eu não tinha experiência em sala de aula, já que entrei } \\
\text { aqui assim que me formei e foi aqui que me deram essa } \\
\text { oportunidade." (Entrevistada 10) } \\
\text { "Eu aprendo a cada dia, com eles (os alunos), com os pais e } \\
\text { com as experiências, é uma forma de aprender e de ensinar" } \\
\text { (Entrevistada 7) }\end{array}$ \\
\hline $\begin{array}{l}\text { Visão da } \\
\text { Organização }\end{array}$ & Valores & $\begin{array}{l}\text { "Os valores trabalhados, não só pela Igreja Evangélica, mas } \\
\text { pelos valores de família, respeito ao próximo" (Entrevistada 9) }\end{array}$ \\
\hline
\end{tabular}




\begin{tabular}{|c|c|c|}
\hline & $\begin{array}{l}\text { Proposta da } \\
\text { Escola }\end{array}$ & $\begin{array}{l}\text { "Vim pela proposta do colégio.... explicou que era um Colégio } \\
\text { que trabalha com projeto social, a visão do Colégio e já gostei, } \\
\text { sendo bem diferente dos outros Colégios que vi" (Entrevistada } \\
\text { 10) }\end{array}$ \\
\hline & $\begin{array}{l}\text { Escola } \\
\text { Evangélica }\end{array}$ & $\begin{array}{l}\text { "Pela forma de como é conduzida, por fazer menção ao } \\
\text { Evangelho, essas coisas eu achei muito importante, o } \\
\text { diferencial do colégio, a forma de educação com essa menção" } \\
\text { "É da Igreja, e eu como sou Evangélica eu optei por esse } \\
\text { trabalho, por ser da igreja e um projeto social, então juntei o útil } \\
\text { ao agradável" (Entrevistada 9) }\end{array}$ \\
\hline \multirow{2}{*}{ Autorrealização } & Se sentir útil & $\begin{array}{l}\text { "Eu estava em casa, estava me sentindo um pouco assim... } \\
\text { inútil, porque eu queria fazer algo pro ser humano, então pensei } \\
\text { assim: vou procurar um emprego e ser útil pra alguém, foi } \\
\text { quando enviei meu currículo e entrei pro CEPRAMOS" } \\
\text { (Entrevistada 8) }\end{array}$ \\
\hline & $\begin{array}{l}\text { Trabalho } \\
\text { Voluntário }\end{array}$ & $\begin{array}{l}\text { "Quando você participa de algo assim, que busca ajudar o } \\
\text { próximo e te agrega é muito bom, então trabalhar como } \\
\text { voluntária pra mim é ótimo" (Entrevistada 4) } \\
\text { "É um trabalho voluntário, é um trabalho social que é muito } \\
\text { bonito e eu quis fazer parte” (Entrevistada 9) }\end{array}$ \\
\hline \multirow{3}{*}{ Ambiência } & $\begin{array}{l}\text { Escola } \\
\text { Familiar }\end{array}$ & $\begin{array}{l}\text { "Já um pouco desacreditada da área da educação, por tudo que } \\
\text { eu passei e por tudo o que eu vi em outras escolas, e aqui eu vi } \\
\text { diferente, não vejo nem como uma escola e nem como uma } \\
\text { equipe, eu vejo como família” (Entrevistada 2) }\end{array}$ \\
\hline & $\begin{array}{l}\text { Qualidade } \\
\text { de vida }\end{array}$ & $\begin{array}{l}\text { "Gostei demais, aqui as pessoas... eu me sinto em casa, tenho } \\
\text { liberdade para conversar com a Diretora, ela para e me ouve, as } \\
\text { pessoas são muito bacanas, são seres humanos muito legais" } \\
\text { (Entrevistada 8) } \\
\text { "É um local que me sinto bem, que eu gosto de trabalhar e } \\
\text { quero crescer e continuar aqui" (Entrevistada 5) }\end{array}$ \\
\hline & Admiração & $\begin{array}{l}\text { "Eu passava em frente à escola e pensava que seria muito bom } \\
\text { dar aula para as crianças nessa Instituição, entrar aqui seria um } \\
\text { sonho, o qual se realizou e hoje dou aula aqui." (Entrevistada 8) }\end{array}$ \\
\hline
\end{tabular}

Quadro 3 Conceitos Emergentes e Categorias Preliminares 
A inserção no mercado de trabalho se diz pela necessidade de ter uma experiência de trabalho, já que alguns voluntários começaram suas carreiras no CEPRAMOS, facilitando posteriormente a entrada destes em outras Instituições; e a necessidade de um emprego, devido a grande dificuldade em arrumarem trabalhos em suas áreas de atuação e que seus perfis se encaixem, evitando estar fora do mercado de trabalho e por fim, apesar de ter remuneração simbólica, a busca pela ajuda financeira. A partir deste conceito, pode-se observar indícios de comprometimento Instrumental, o qual o voluntário tem o objetivo de permanecer na empresa não por sentimento de pertencimento, mas pela necessidade dos benefícios que a empresa traz, seja de experiência profissional, ou a mínima ajuda de custo.

A visão da organização se diz aos voluntários se verem identificados com a proposta da escola, a forma educacional que visa não só a parte literal da escolaridade, mas a composição moral e cívica dos alunos; os valores pregados pela Instituição, baseados em lealdade, verdade, família, respeito, etc.; A escola Evangélica é vista pelos funcionários como importante para a sociedade e para estes mesmos, de acordo com a visão de mundo adquirida pelos voluntários. Esta visão demonstra traços da Identificação Organizacional, já que os valores e objetivos da organização são coerentes e semelhantes com os valores e objetivos do voluntário inserido.

A autorrealização se diz pela necessidade do indivíduo de se tornar mais e mais o que querem ser e o que são capazes de ser, então, dedicando seu potencial a algo com valor como o trabalho voluntário e poder se sentir útil juntando o trabalho voluntário com atividades que os tornam predispostos a se sentirem realizados. Estes voluntários sentem-se valorizados e têm orgulho em estar na empresa, se colocando à disposição para contribuir em prol da organização e demonstrando vínculo emocional, ou seja, indícios do Comprometimento Afetivo.

A ambiência é a forma como os voluntários se sentem à vontade no trabalho, para estes estar em uma empresa que é uma família, um auxiliando o outro trazem a sensação de uma Escola Familiar; a abertura de comunicação entre os voluntários com a Direção da Instituição, a liberdade de expressão, o se sentir bem no local, estes traduzem uma qualidade de vida, a admiração pela proposta da escola e pela forma que é gerida definem a ambiência para estes voluntários. 


\subsubsection{Sentimentos sobre a Organização}

$\mathrm{Na}$ pesquisa realizada, ao falarmos das motivações existentes para os voluntários estarem na Instituição, foram abordados questionamentos sobre os sentimentos que eram despertados nestes ao trabalharem na organização, uns entrevistados definiram com apenas um sentimento e outros com um conjunto destes.

No quadro 4 podemos visualizar alguns trechos das entrevistas, onde os voluntários demonstram seus sentimentos ao serem questionados.

\begin{tabular}{|l|l|}
\hline Entrevistada 6 & "O sentimento que eu tenho por estar aqui é amor" \\
\hline Entrevistada 7 & $\begin{array}{l}\text { "Nossa, é um mix de sentimentos, seria amor, carinho, respeito, } \\
\text { gratidão..." }\end{array}$ \\
\hline Entrevistada 10 & $\begin{array}{l}\text { "Eu sou muito grata por este lugar, pelo espaço que deram a } \\
\text { mim, gratidão seria o sentimento" }\end{array}$ \\
\hline Entrevistada 1 & "Este lugar me dá paz, tranquilidade..." \\
\hline
\end{tabular}

\section{Quadro 4 Sentimentos}

O gráfico 1 apresentado abaixo demonstra a quantidade de vezes e a proporção de cada Sentimento relatado, sendo assim, a partir dessa análise, os mais descritos pelos entrevistados foram, respectivamente, Amor, Respeito, Gratidão e Bem-estar. 


\section{Gráfico 1 Sentimentos}

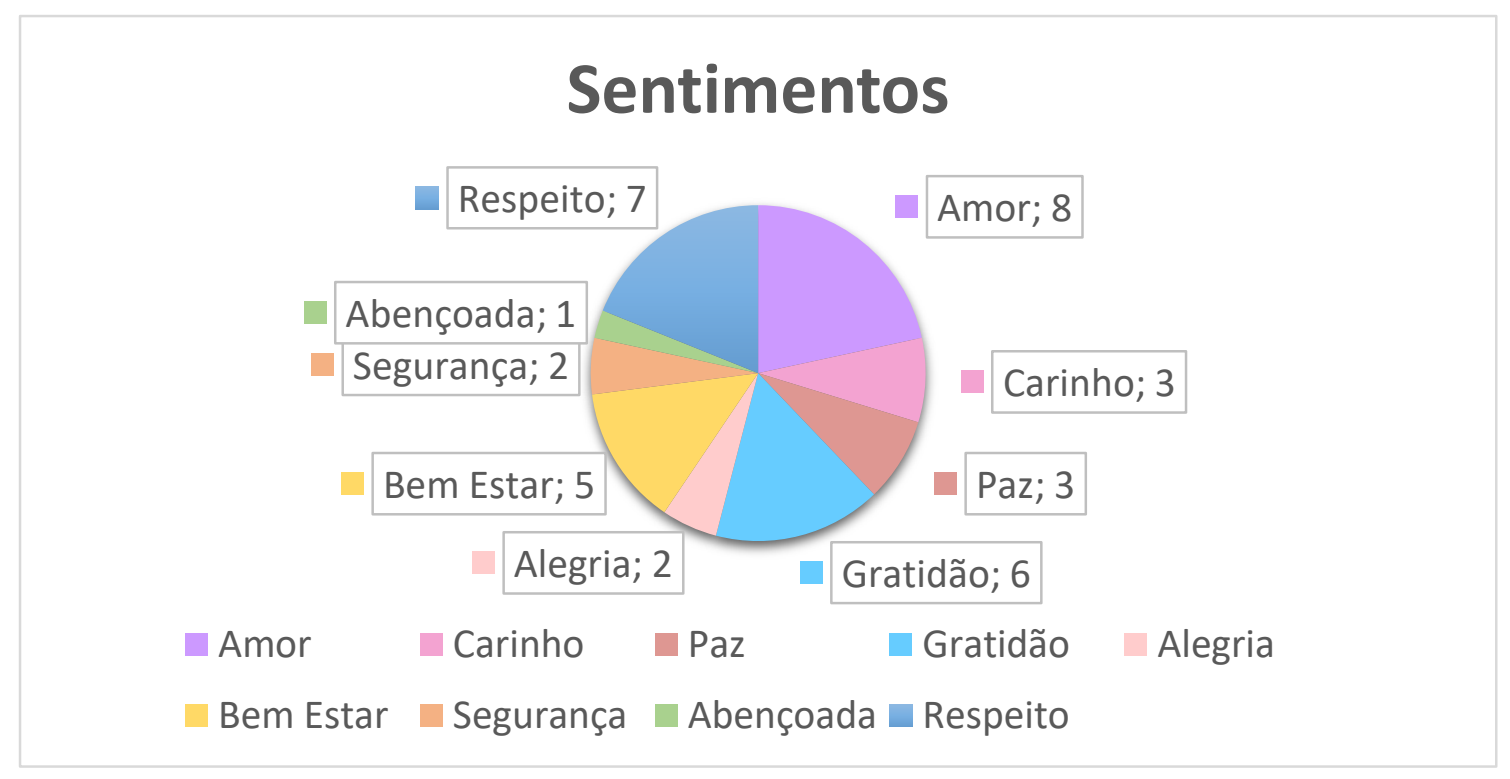

Ao analisarmos os sentimentos apresentados, podemos ver a importância destes para o entendimento do vínculo organizacional. Os sentimentos demonstram indícios do vínculo através do Comprometimento Afetivo, já que os voluntários sentem felicidade e gratidão em pertencer a organização; o seu vínculo emocional em demonstrar amor pelo trabalho, bem-estar em fazer parte da organização, sentir respeito pela forma de trabalho, isso evidencia o significado de pertencimento, sendo assim, o que a organização proporciona a estes voluntários.

\subsubsection{Visão do funcionário sobre a Instituição}

Neste estudo foi abordada a visão que os funcionários possuem da organização, definindo o CEPRAMOS em forma de palavras para demonstrar seus conceitos sobre a Instituição de Ensino.

No quadro abaixo podemos visualizar alguns trechos das entrevistas, onde os voluntários definem a Instituição com sua visão ao serem questionados. 


\begin{tabular}{|c|c|}
\hline Entrevistada 8 & $\begin{array}{l}\text { "Eu descreveria como Amor, Carinho e } \\
\text { Compromisso" }\end{array}$ \\
\hline Entrevistada 9 & "Amor, Dedicação e Profissionalismo" \\
\hline Entrevistada 10 & $\begin{array}{l}\text { "Em Primeiro lugar o Amor de Deus, } \\
\text { Compromisso e Família" }\end{array}$ \\
\hline Entrevistada 7 & $\begin{array}{l}\text { "Eu descreveria o CEPRAMOS com muito } \\
\text { Amor, muito Respeito e muita Gratidão..." }\end{array}$ \\
\hline
\end{tabular}

\section{Quadro 5 Definições}

O gráfico 2 apresentado demonstra a quantidade de vezes e a proporção de cada visão sobre a organização, então, a partir dessa análise, as palavras mais utilizadas para a definição da Instituição de Ensino pelos entrevistados foram, respectivamente, Amor, Família, Valores e Cuidado.

\section{Gráfico 2 Definições}

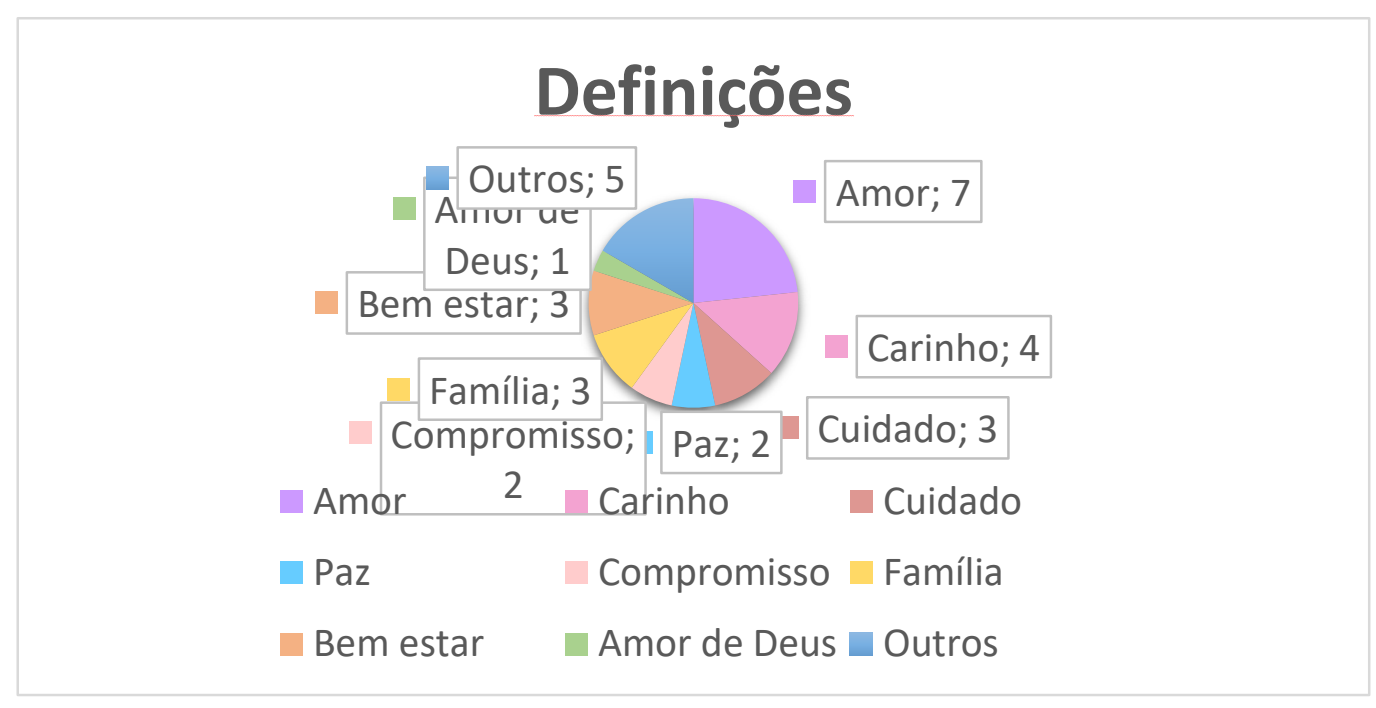

Ao analisarmos as definições do CEPRAMOS de acordo com a visão dos voluntários, consegue-se observar a importância desta visão para o vínculo organizacional, já que, para muitos voluntários estar em um ambiente que as pessoas são tratadas como família e demonstram o amor entre estes, pelas crianças e pelo trabalho, evidencia indícios da Identificação Organizacional, sendo ligações psicológicas profundas entre os voluntários e a Instituição de Ensino, pois as palavras evidenciadas são todas positivas e de acordo com os valores pregados pelos indivíduos e pela organização. 


\subsection{Integração do Indivíduo à Organização}

Ao decorrer das entrevistas, foram analisados pontos em que o que a Instituição traz ao indivíduo e que acrescenta em sua vida ou dia a dia, para que ele esteja inserido na organização. Para detalhar esse tópico, serão utilizados novamente as categorias preliminares e respectivos conceitos emergentes relevantes sobre o fenômeno.

\begin{tabular}{|c|c|c|}
\hline $\begin{array}{l}\text { Conceito } \\
\text { Emergente }\end{array}$ & $\begin{array}{l}\text { Categoria } \\
\text { Preliminar }\end{array}$ & Trecho da Entrevista \\
\hline \multirow{3}{*}{$\begin{array}{l}\text { Crescimento } \\
\text { Pessoal }\end{array}$} & $\begin{array}{l}\text { Paz de } \\
\text { Espírito }\end{array}$ & $\begin{array}{l}\text { "Me sinto muito bem, principalmente por ser evangélico, } \\
\text { que a gente pode entrar pra trabalhar e é um local } \\
\text { tranquilo... onde tem segurança e paz de espírito, uma } \\
\text { paz espiritual" (Entrevistada 1) }\end{array}$ \\
\hline & Aprendizado & $\begin{array}{l}\text { "Assim, é um aprendizado todos os dias, todos os dias a } \\
\text { gente aprende um pouquinho, a gente vem pra cá com } \\
\text { um planejamento de aula, hoje vou fazer isso e aquilo, } \\
\text { mas muitas vezes a gente chega aqui e se depara com } \\
\text { uma porção de crianças com problemas dentro de } \\
\text { casa...ou de saúde ou com os pais, se deparando com } \\
\text { muitas situações.." (Entrevistada } 7)\end{array}$ \\
\hline & Amizades & $\begin{array}{l}\text { "eu aprendi muita coisa, ganhei muitas amizades boas..." } \\
\text { (Entrevistada 5) }\end{array}$ \\
\hline \multirow{2}{*}{$\begin{array}{l}\text { Crescimento } \\
\text { Profissional }\end{array}$} & $\begin{array}{l}\text { Experiência } \\
\text { de Trabalho }\end{array}$ & $\begin{array}{l}\text { "Estou tendo oportunidade de crescer internamente e } \\
\text { profissionalmente, tendo essa possibilidade e autonomia } \\
\text { para criar e, também, o trabalho com outras professoras } \\
\text { que possuem mais experiência, acaba aprendendo } \\
\text { bastante" (Entrevistada 2) }\end{array}$ \\
\hline & $\begin{array}{l}\text { Descoberta } \\
\text { Profissional }\end{array}$ & $\begin{array}{l}\text { "Eu gosto de criança e queria ver como era a } \\
\text { experiência...eu acho que pelo fato de eu não saber o que } \\
\text { eu queria, e agora eu sei, agora quero fazer Pedagogia, } \\
\text { foi o que eu adquiri estando aqui" (Entrevistada 11) }\end{array}$ \\
\hline
\end{tabular}

Quadro 6 Conceitos Emergentes e Categorias Preliminares Integração do Indivíduo 
Ao ser abordado o quanto a organização agrega a estes indivíduos, ficou claro a descrição sendo conveniente com o crescimento tanto pessoal quanto profissional. Cada voluntário em entrevista deu um lado pessoal e um lado profissional para dizer o que ganham por estar na organização, sendo o trabalho como um todo importante para a integração pessoal.

O crescimento pessoal se dá ao lado espiritual da organização, por ser uma organização evangélica, as pessoas se sentem confortáveis estando em um ambiente que condiz com seus pensamentos, trazendo paz espiritual para sua vida; um aprendizado constante por ter que entender como lidar com as crianças, por elas terem seus problemas familiares, os quais afetam seu desenvolvimento escolar; e, por fim, as amizades que são construídas na organização, como já levantado anteriormente, a empresa tem um ambiente familiar, o que facilita a interação dos funcionários e a criação de vínculos de amizade entre eles.

O crescimento profissional se dá pelas experiências constantes no trabalho, a forma que lidam com as crianças e com os pais trazem novas experiências profissionais, e também, com o constante desafio em ter criatividade para tornar as aulas mais atrativas e liberdade de atuação em sala de aula; a descoberta profissional se dá aos voluntários que começaram na organização a sua jornada de trabalho, dando a direção a ser seguida na vida profissional. 


\section{Conclusão}

O objetivo central do presente trabalho consistiu em analisar como os voluntários estão vinculados a organização, se estão comprometidos ou identificados. Para atingi-lo foram estabelecidas as seguintes categorias temáticas de análise: Motivações (Motivos de pertencer, sentimentos despertados pela Instituição e a Visão do voluntário) e Integração ao Indivíduo.

Da análise da categoria "Motivações" identifica-se como motivos principais para os voluntários estarem na Instituição se dão: a inserção no mercado de trabalho, a visão da organização, a autorrealização e a ambiência, demonstrando as necessidades do indivíduo. Dessas, a variáveis "Inserção no mercado de trabalho" e "Visão da organização", foram as mais relevantes para a determinação dos fatores que mais influenciam para o vínculo dos funcionários a organização, já que estes são os que mais foram levantados como motivações para estarem na organização que estão inseridos. Da análise da categoria "Sentimentos" identifica-se como fatores determinantes do que a organização desperta no indivíduo: o amor, a gratidão o carinho e o respeito, tendo como maior resposta o AMOR, já que é assim que os voluntários pensam das crianças, do trabalho e da proposta da organização. A gratidão se dá pela oportunidade de estar empregado e pela oportunidade de fazer parte de uma organização com os preceitos do CEPRAMOS. O carinho e o respeito se dão pelo fato de se sentirem bem ambientados e pela visão da organização. Da análise da categoria "Definições da Instituição" identifica-se como fatores determinantes para este estudo, as palavras Amor, Família, Valores e Cuidado. A palavra amor surge novamente como conceito geral da Instituição, trabalho e pessoas; A Família surge pelo fato de os voluntários terem amizades e se sentirem em casa, bem integrados e se sentindo como família para alcançar os objetivos da organização. Os Valores são bem claros e importantes para os voluntários, isso define a visão da organização, assim como o cuidado, com o trabalho exercido com as crianças e com os pais, já que estes veem a organização como forma de alcançar vidas para o evangelho.

E, por fim, da categoria "Integrações ao Indivíduo" identifica-se como fatores determinantes que agregam ao indivíduo: o crescimento profissional e 0 crescimento pessoal. $O$ crescimento profissional se dando através de experiências e descobertas profissionais e o crescimento pessoal, através do aprendizado, da paz de espírito e as amizades. 
Em síntese, foi possível identificar, pelos depoimentos dos indivíduos que responderam à pesquisa, que a razão destes voluntários estarem vinculados ao Centro Educacional do Primeiro Amor - Obras Sociais, é a identificação com a Organização, ou seja, o vínculo criado entre voluntário e organização é profundo, pois os objetivos pessoais estão em coerência com os objetivos do CEPRAMOS, tornando estes importantes para o voluntário, dando a ele incentivo para a determinação do sucesso da organização. A partir do conceito de relação entre Identificação Organizacional e Comprometimento Organizacional, consegue-se observar que o comprometimento afetivo está evidente nas relações de vínculo do Colégio CEPRAMOS, mas que vão além do comprometimento, os voluntários sentem-se pertencentes à organização de forma completa, evidenciando assim a Identificação.

O estudo realizado apresentou limitações importantes quanto aos seus dados levantados, já que o entrevistador faz parte do corpo de voluntários da organização em questão; podendo assim sofrer influência sobre o que foi dito nas entrevistas e com o que foi interpretado na análise do presente estudo, não podendo separar esta informação do processo de pesquisa.

Com este estudo, há evidências da possibilidade de estabelecer fatores explicativos de vínculos organizacionais, o que motivam seus funcionários a se vincularem a organização do terceiro setor. Entender esses fatores motivacionais auxiliam aos gestores na forma de recrutarem e reterem os funcionários, já que poderá ser traçado um modelo de perfil de voluntário para que o indivíduo que integre a organização, esteja de acordo com os preceitos e objetivos desta. Diminuindo assim a possibilidade de turnover e aumentando as chances de obterem sucesso nos objetivos estabelecidos da organização, a partir do comprometimento do voluntário que foi captado.

Para entendimento melhor do processo de vínculo em empresas do terceiro setor, o interessante para um próximo estudo seria entender como os líderes das organizações tem papel na construção dos vínculos dos voluntários, já que estes são parte importante no desenvolvimento da organização como um todo. 


\section{Referências Bibliográficas}

ANTHONY, Peter \& BERETE, Moussa. Normative Organizational Commitment and its Effects on Employee Retention, Business and Economic Research ISSN 2162-4860 2016, Vol. 6, No. 1

ASHFORTH, B. E., HARRISON, S. H., \& CORLEY, K. G. Identification in organizations: an examination of four fundamental questions. Publicado em Journal of management, 34(3), 325-374, Ano de 2008.

ASHFORTH, B. E., \& MAEL, F. Social identity theory and the organization. Publicado na Academy of Management Review, 14(1), 20-39, Ano de 1989.

BALASSIANO, M., \& COSTA, I. S. A. (2006). Gestão de carreiras: dilemas e perspectivas. São Paulo: Atlas.

BALLASIANO, Moisés \& SALLES, Denise, Perceptions of Equity and Justice and Their Implications on Affective Organizational Commitment: a Confirmatory Study in a Teaching and Research Institute, Publicado em BAR, Rio de Janeiro, v. 9, n. 3, art. 2, pp. 268-286, July/Sept. 2012

BEYDA, Tânia Tisser, MACEDO-SOARES, T. Diana. Identidade Organizacional: análise crítica da produção acadêmica brasileira de 2004 a 2009. Publicado em Revista De Administração, v.45, № 4, São Paulo, Dez. de 2010.

BUSSELL, H. e FORBES, D., Understanding the volunteer market: the what, where, who and why of volunteering. Publicado no International Journal of Nonprofit Volunteer Sector Marketing, vol. 7,n.ํㅜ 3, pp. 244-257, Ano de 2002.

CHIAVENATO, Idalberto Introdução à Teoria Geral da Administração, 4a Edição, Editora Compacta, 2014.

CHANLAT, J. Por uma antropologia de condição humana nas organizações. Publicado em CHANLAT, J (Coord.). O indivíduo na organização, dimensões esquecidas, 3ª Edição, São Paulo, Atlas, v.1, Ano de 1996.

CNAAN, R. A. e CASCIO, T., Performance and commitment: issues in management of volunteers in human service organizations. Publicado no Journal of Social Service Research, vol. 24, n. 3/4, Ano de 1998.

CNAAN, R.A., \& GOLDBERG-GLEN, R.S. Measuring motivation to volunteer in human services. Publicado em Journal of Applied Behavioral Science, 27(3), 269-284, Ano de 1991.

DA SILVA, Reinaldo O. Teorias da Administração, São Paulo, Editora ABDR, 2008.

DE SOUZA, Luccas Melo. LAUTERT, Liana, Trabalho voluntário: uma alternativa para a promoção da saúde dos idosos. Publicado em Revista Escolar de Enfermagem da USP, São Paulo, 2007.

DOS SANTOS, Alziro Alves, VIEIRA, Adriane, GARCIA, Fernando Coutinho Identificação Organizacional: o caso dos professores de uma instituição 
federal de ensino, publicado em Revista Gestão e Planejamento, Salvador, v. 14, n. 1, p. 3-17, jan./abr. 2013.

EDWARDS, M. R. Organizational identification: A conceptual and perational review. Publicado no International Journal of Management Reviews, 7(4), 207230, Ano de 2005

ELLENBECKER, C. H., \& CUSHMAN, M. Home healthcare nurse retention and patient outcome model: Discussion and model development. Publicado no Journal of Advanced Nursing, Ano de 2012

FEDVYCZYK, Gabriela Ambrosio, SOUZA, Adalberto Dias. 0 comprometimento organizacional de trabalhadores nas bases: afetiva, instrumental e normativa. Apresentado no VIII Encontro de Produção Científica e Tecnológica, Outubro de 2013.

FERREIRA, Marisa, PROENÇA, Teresa e PROENÇA, João F. As motivações do trabalho voluntário. Publicado em Revista de Gestão dos Países de Língua Portuguesa, v.7, n. 3, Lisboa, Julho de 2008.

FREDERICK J. SLACK, John N. Orife, and Fred P. Anderson, "Effects of Commitment to Corporate Vision on Employee Satisfaction with Their Organization: An Empirical Study in the United States," International Journal of Management 27, no. 3 (2010)

GOMES, José Osmar, FANTINEL, Letícia Dias, PALASSI, Márcia Prezotti, DA SILVA, Alfredo Rodrigues Leite Identificação e alteridade na identidade organizacional de uma organização pública, Instituto de Defesa Agropecuária e Florestal do Espirito Santo, DEARH - Departamento de Administração e Recursos Humanos, publicação online em 22 de novembro de 2016.

GOMES, J. O.; FANTINEL, L. D.; PALASSI, M. P.; SILVA, A. R. L. Identificação e alteridade na identidade organizacional de uma organização pública. Publicado em Administração Pública e Gestão Social, v. 8, n. 4, p. 257-269, 2016.

KAUR, Kanwaldeep, SANDHU, H. S. Career Stage Effect on Organizational Commitment: Empirical Evidence from Indian Banking Industry. Publicado em International Journal of Business and Management, Vol. 5, nº 12, Ano 2010.

LATHAM, G. P. e PINDER, C. C., Work motivation theory and research at the dawn of the Twenty-First Century. Publicado na Revista Annual Reviews Psychology, vol. 56, pp. 485-516, Ano de 2005.

LAU, Elaine, W. K. The Effect of Employee Engagement on Continuance and Normative Commitment to the Organization. Artigo apresentado em Southwest Decision Sciences Institute 42nd Annual Conference, 2011 Houston, TX.

LIMA, Aldo José Fossa de Souza Lima, BARELI, Paulo, A importância Social do Desenvolvimento do Trabalho Voluntário, Publicado em Revistas de Ciências Sociais, Vol. 14, № 20, 2010.

MACHADO, H. V.Identidade organizacional: um estudo de caso no contexto da cultura brasileira. RAE, 2005. 
MAXIMIANO, Antônio Cesar Amaru, Introdução à Administração, 5ª Edição, São Paulo, Editora Atlas, 2000.

MENDES, Ana Margarida Vieira identificação organizacional, satisfação organizacional e intenção de turnover: estudo com uma amostra do setor das telecomunicações, Universidade de Lisboa, 2014.

NICHOLS, G. and KING, L. Volunteers in the Guide Association:problems and solutions', Publicado no VoluntaryAction,Vol.1,No.1,pp.21-32, Ano de 1998

OKUN, M. e EISENBERG, N. Motives and intent to continue organizational volunteering among residents of a retirement community area. Publicado no Journal of Community Psychology, Vol. 20, pp. 183-187, Julho de 1992.

PRATT, M. G.; FOREMAN, P. O. Classifying managerial responses to multiple organizational identities. The Academy of Management Review, 2000.

PRATT, M. G. 1998 "To be or not to be: Central questions in organizational identification." In Whetten, D., Godfrey, P. (eds.), Identity in Organizations: Developing Theory Through Conversations. Thousand Oaks, CA

RAVASI, Davide PRATT, Michael, SCHULTZ Majken e ASHFORTH, Blake Organizational Identity, culture and image, incluído no livro Oxford Handbook of Organizational Identity, publicado em Oxford University Press, Outubro de 2011.

RIFKIN, J. The End of Work: The Decline of the Global Labour Force and the Dawn of the Post-market Era. Publicado em Putnam, New York, Ano de 1995.

RIKETTA, M., e VAN DICK, R. Foci of attachment in organizations: A metaanalytic comparison of the strength and correlates of workgroup versus organizational identification and commitment. Publicado no Journal of Vocational Behavior, 67(3), 490-510, Ano de 2005.

RIKETTA, M. Organizational identification: A meta-analysis. Publicado no Journal of Vocational Behavior, 66(2), 358-384, Ano de 2005.

REBOUÇAS, Djalma De P. Planejamento Estratégico: Conceitos, metodologia e práticas. 23ํㅡㄹ Edção, São Paulo, Editora Atlas S.A., 2007.

REGO, A. Comprometimento afetivo dos membros organizacionais: o papel das percepções de justiça. Revista de Administração Contemporânea, 2002 ROMERO, Maria José de Souza, GARCIA, Fernando Coutinho, Um estudo de caso entre docentes de uma instituição superior. Publicado em Revistas de Ciências Sociais, Vol. 15, № 21, Ano de 2011.

ROSSI, Roberta - Ênfase e Foco no Voluntariado Empresarial, 2010

SAMPAIO, Jáder dos Reis - Voluntários: um estudo sobre a motivação de pessoas e cultura em uma organização do terceiro setor, São Paulo, 2004

SANTOS, A. A. D., VIEIRA, A., \& GARCIA, F. C. Identificação organizacional: $O$ caso dos professores de uma instituição federal de ensino. Publicado na 
Revista Gestão \& Planejamento, 14(1), 3-17, Ano de 2013.

SIMON, Juliane, COLTRE, Sandra Maria, 0 Comprometimento Organizacional afetivo, instrumental e normativo: estudo de caso de uma empresa familiar. Publicado em Qualit@s Revista Eletrônica ISSN 16774280 Vol.13. No 1 (2012)

SLACK, Frederick J.; ORIFE, John N.; ANDERSON, Fred P. Effects of Commitment to Corporate Vision on Employee Satisfaction with Their Organization: An Empirical Study in the United States. Publicado na Academic Journal Article, International Journal of Management, ano de 2012.

SNYDER, M. E DEBONO, K. G. A functional approach to attitudes and persuasion, Publicado em Wymer, W. W, Ano de 1987.

SHIN, S. e KLEINER, B. H., How to manage unpaid volunteers in organisations. Publicado na Revista Management Research News, vol. 26, n.ำ 2/3/4, 2003.

TAJFEL, H. Social psychology of intergroup relations. Annual Review of Psychology, 33(1), 1-39, Ano de 1982.

VAN DICK, R. Identification in organizational contexts: Linking theory and research from social and organizational psychology. Publicado no International Journal of Management Reviews, 3(4), 265-283, Ano de 2001.

VAN DICK, R., Christ, O., STELLMACHER, J., WAGNER, U., Ahlswede, O., Grubba, C., HAUPTMEIEr, M., TISSINGTON, P. A. Should I stay or should I go? Explaining turnover intentions with organizational identification and job satisfaction. Publicado no Jornal British Journal of Management, 15(4), 351360, Ano de 2004.

VAN KNIPPENBERG, D., \& VAN SCHIE, E. C. M. Foci and correlates of organizational identification. Publicado no Journal of Occupational and organizational Psychology, 73(2), 137- 147, Ano 2000.

Sites

Agência de Notícias IBGE, Cerca de 6,5 milhões de pessoas fazem trabalho voluntário no país. Publicado em 23/03/2018. Acessado em: 10/05/2018 <https://agenciadenoticias.ibge.gov.br/agencia-noticias/2012-agencia-denoticias/noticias/20618-cerca-de-6-5-milhoes-de-pessoas-fazem-trabalhovoluntario-no-pais.html> 
Centro de Voluntariado de São Paulo, Fragmentos da História do Voluntariado no Brasil. Publicado em 2016. Acessado em: 12/05/2018. < http://www.voluntariado.org.br/default.php?p=texto.php\&c=linha_tempo>

Presidência da República - Casa Civil - Subchefia para assuntos Jurídicos, Constituição da Rebública Federativa do Brasil de 1988. Acessado em: 05/04/2018. < http://www.planalto.gov.br/ccivil_03/constituicao/constituicao.htm> 